\title{
DIVERSIFICATION OF FACTORS INFLUENCING QUALITATIVE EVALUATION OF A HISTORICAL AND CULTURAL DESTINATION
}

\author{
JUAN ZHANG \\ Shinawatra University, School of Management, Bangkok, Thailand \\ Mailing address: Juan Zhang, School of Electronic Commerce, Nanyang Institute of Technology, Nanyang, \\ 80 Changjiang Road, Henan, China, tel.: +13949365688, e-mail: zhangjuan02331@163.com
}

\begin{abstract}
Introduction. Perceived quality combined with tourist motivation, tourist experience and other variables were identified as important antecedents of tourist satisfaction and destination loyalty. However, few studies have examined factors influencing a tourist's perception of the service quality in a destination, especially in specific destinations. The main purpose of this study was to investigate whether tourist motivation and tourist experience influence how tourists perceive quality and to analyse complex relationships between the constructs of perceived quality, tourist experience, tourist motivation and tourist satisfaction in the context of historical and cultural destinations. Material and methods. A survey of 1,389 tourists who visited an ancient town in the center part of China served as the basis for analysis. Structural equation modelling was employed to test the proposed hypotheses. Results. The empirical results showed that tourist motivation and tourist experience exerted a significant positive influence on perceived quality. These three variables had a simultaneous significant positive impact on tourist satisfaction. The results also revealed the mediating effects of tourist experience and perceived quality in the proposed model. Conclusions. The article verified a model regarding the relationships between tourist motivation, tourist experience, perceived quality and tourist satisfaction. According to the results, a historical and cultural destination could improve a tourist's perceived quality and satisfaction by enhancing tourist experience and providing tourist stimuli.
\end{abstract}

Key words: historical and cultural destination, tourist experience, perceived quality, tourist motivation, tourist satisfaction

\section{Introduction}

Perceived quality was defined as the customer's perception of the overall quality of a product or service [1]. In tourism, destination managers and experts also pay much attention to perceived quality and relevant concepts such as tourist satisfaction. The related literature can be dated back to the Outdoor Recreation Resources Review Commission reports of 1962 [2]. Generally, tourists' perception of the quality of an attraction is the determinant of their choice, evaluation and satisfaction with a specific attraction. Also, high perceived quality and high tourist satisfaction result in tourist loyalty and revisit, more tolerance of an increase in prices and a rising fame of the attraction [2]. It is very helpful for the destination to attract both new tourists through positive word-of-mouth communication as well as new public tax investment and private investment to improve the development of the destination. Because of the contribution of perceived quality to destination marketing, a lot of studies related to this issue have been conducted. However, most of them focused on the effects of perceived quality and took perceived quality as the antecedent of other variables such as perceived value [3], tourist satisfaction [4, 5], and tourist behavioural tendency [6]. There has been relatively little discussion on the factors influencing how tourists perceive quality.

Tourist experience is a specific kind of service experience. According to Pine and Gilmore [7], besides consuming products and services, consumers seek unique and memorable experiences during their consumption process. Service experience is subjective personal feelings and reactions consumers have when they make use of service [8]. For tourism service, most tourists travel to get experience different from daily life. Especially for cultural and historical tourism, it is basically an experiential consumption, and tourists come to seek, see or feel the history and past, either glorious or painful. The quality of experience was proven to have a direct impact on perceived value and satisfaction in heritage tourism [8]. Because perceived quality of a historical and cultural destination is the tourist's perception of the overall quality of the attraction, it seems intuitively logical that there should be a causal link between tourist experience and perceived quality in a historical and cultural destination. The quality of the experience that tourists feel influences their perception of the quality of the destination.

Tourist motivation is the intrinsic and extrinsic power that directly promotes people's behaviour connected with tourism [9]. They choose to visit a specific destination due to different motivations. For example, some want to acquire new knowledge, others wish to appreciate beautiful scenery, while another group may have other purposes. It was noted that tourist motivation had an impact on perceived quality [10] and tourist satisfaction [11].

The first purpose of this study was to investigate whether tourist experience influences perceived quality of the tourist as an antecedent within historical and cultural tourism context. The second purpose was to explore complex relationships between four important variables, i.e., tourist motivation, tourist experience, perceived quality and tourist satisfaction in the context of historical and cultural tourism. The proposed hypothetical model is depicted in Figure 1.

\section{Conceptual Background and Hypotheses}

\section{Tourist Motivation}

Motivation is defined as psychological/biological needs and wants which arouse, direct and integrate a person's behaviour and activity [12]. Tourist motivation is the intrinsic power that directly promotes people's tourist behaviour [6]. Researchers 


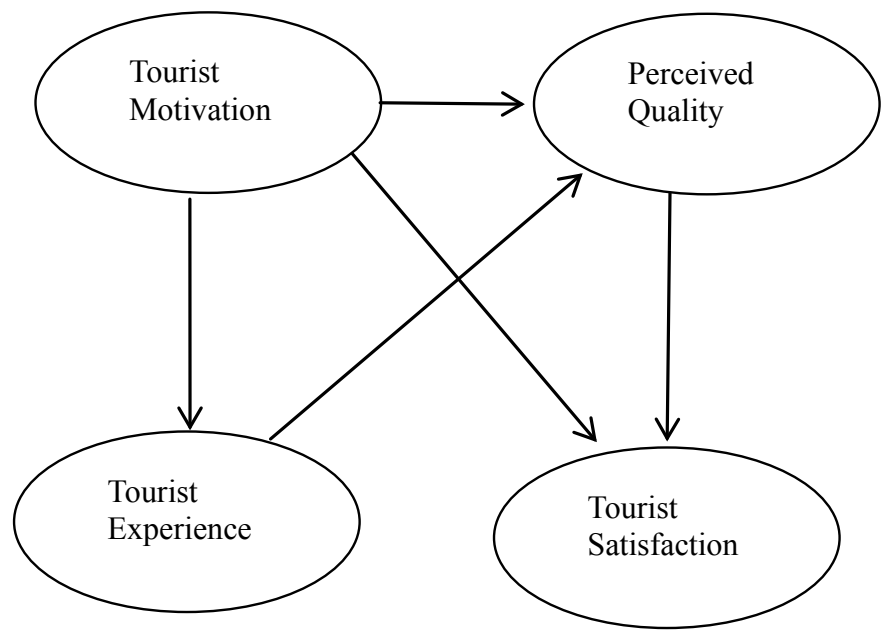

Figure 1. Proposed Hypothetical Model

have highlighted the significance of visitors' motivations in the selection of attractions, perception of the quality of attractions, satisfaction level of attractions and behavioural tendency after visiting the attractions, based on intrinsic and extrinsic factors $[9,11,13]$. An intrinsic motive was one's desire to search out new things to gain knowledge [14]. For tourists, the intrinsic motive was the psychological or social motive that drives visitors to travel [15], such as escaping reality, relaxation, exercising, adventure and exploration, which is called push motivation by some researchers nowadays. The extrinsic motive, also known as pull motivation, involved the performance of an activity to attain a desired outcome in the context of tourism, for motivations related to the attributes of the tourist destination or activities provided by the destination which attract tourists, e.g. natural scenery, leisure facilities, cultural atmosphere, events and catering [15]. For a historical and cultural destination, the motivations that drive tourists to come and visit are of evident difference. Tourists may seek historical clues of the past, experience history, appreciate heritage and relics or just have special sightseeing. Therefore, unlike other kinds of destinations based on very different motivations of visitation, it is not strange that different tourists may have very different, even opposite, feelings and reactions (different experiences) for a specific historical and cultural destination. Thus, in this work, the following hypotheses were put forward:

$\mathrm{Hl}$ : Tourist motivation has a significant impact on perceived quality.

H2: Tourist motivation has a significant impact on tourist experience.

H3: Tourist motivation has a significant impact on tourist satisfaction.

\section{Tourist Experience}

Pine and Gilmore [7] claimed that we were in an era of rapid development of experience economy. Tourism is obviously one of the pioneer fields of the experience economy. Tourist experience became an important research issue in the 1960s and grew to be popular in the social science literature by the 1970s [16]. However, at that time tourist experience was discussed fragmentarily. After the 1990s, systematic research approaches, from qualitative to quantitative studies, were used to study tourist experience [17].

In studies on tourism, experiences were viewed as the emotional, physical, spiritual or intellectual state of being when a person was involved in an event or a special place [7, 18]. It was a complicated psychological process that was different from everyday experiences [19]. Although there are various definitions of tourist experience, researchers agreed that tourist experience was a subjective and personal concept [20]. Therefore, it can only be explained and understood with regard to specific individuals involved and the specific environment where experiences grew out [21]. After discussing several cogent models of tourist experience formation, Prentice [22] also argued that tourist experience and motivations were as diverse as the characteristics of destinations and tourists. Therefore, for historical and cultural destinations that individuals visit mainly to seek special experience, tourist experience and motivation may have unique characteristics and influence the overall perception of the quality of the service provided.

H4: Tourist experience has a significant impact on perceived quality.

It was widely accepted that perceived quality influenced customer satisfaction. However, in tourism research, the experience quality was also found having a positive effect on tourist satisfaction [23]. Oliver and Linda [24] believed that customer satisfaction is generated when customers' expectations formed based on their consumption experience are consistent with their consumption experience.

H5: Tourist experience has a significant impact on tourist satisfaction.

\section{Perceived quality}

Perceived quality is how customers feel and perceive the quality of the product or service they purchased. Researchers attached great attention to perceived quality of service in the tourism context. A lot of studies have been carried out on tourists' perceptions of service quality as they travel [25, 26], and perceived quality was identified as a critical determinant of tourist satisfaction [27].

H6: Perceived quality has a significant impact on tourist satisfaction.

A well-known conceptual model for service quality, SERVQUAL, was initially proposed by Parasuraman, Zeithaml and Berry in 1985, and redefined in 1988 by subdividing it into five dimensions: reliability, responsiveness, empathy, assurance and tangibility [28]. Many other models were developed based on the SERVQUAL model. Wu and Li [29] proposed the SERVPERF model to evaluate visitors' perceptions of museum service. HISTOQUAL was established to investigate perceived quality in the cultural and heritage tourism context [30]. Also, MUSEQUAL was developed to assess museum visitors' experience of service and their satisfaction [31].

\section{Material and Methods}

\section{Questionnaire design and operationalisation of constructs}

The four variables in this study are latent variables that cannot be measured directly. Hence, the observed variables were designed in the questionnaire as the survey instrument based on a thorough literature review and in-depth interviews with experts, with the peculiarities of the destination taken into account. The questionnaire included two parts. Part A contained three sets of questions to measure tourist experience, motivation, perceived quality and satisfaction with 53 items using the five-point Likert's scale as the response format. Part B consisted of 11 questions reflecting the respondents' demographic information and travel behaviours. 
Operationalisation of tourist experience. There were no uniform measurements of tourist experience. In several empirical studies on tourist experience, the construct was measured in different ways. Wang and Mei [6] used perceived quality of services received by tourists as the measurement of tourist experience. Otto and Ritchie [32] developed a four-factor experience scale including hedonics, peace of mind, involvement and recognition. From a different point of view, Kao, Huang, and $\mathrm{Wu}$ [33] put forward four other dimensions of tourist experience, i.e. immersion, surprise, participation and fun.

Based on Pine and Gilmore's four realms of experience [7], Oh, Fiore and Jeoung [34] developed a questionnaire to measure tourist experience and consequence variables following Churchill's [35] procedure for developing a measurement scale. The survey was conducted on 419 guests of B\&B facilities in a Midwestern state of the United States. The experience scales were proven empirically reliable and valid [34]. The scenario of their research was similar to this study. Therefore, this study adopted the measurement scale of tourist experience with minimal changes to reflect specific offerings and situations of the specific ancient town.

There were four main sections to identify the four dimensions of the tourists' experience of the attraction, namely education (The experience has made me more knowledgeable......), aesthetics (I felt a real sense of harmony......), entertainment (It's interesting to visit here.....) and escapism (I completely escaped from reality......), with each dimension including four items. Respondents were required to determine the degree to which each statement reflects their experience of visiting the ancient town along a five-point scale $(1=$ strongly disagree and $5=$ strongly agree).

Operationalisation of perceived quality. To measure the perception of tourists on the quality of the attraction and the services provided, questions were adapted from SERVQUAL Battery [36]. The instrument of SERVQUAL was widely employed in service quality research [37] and the reliability and validity of the instrument were proven by numerous studies [38, 39]. According to the Evaluation and Measurement System of Tourism Attractions in China released by China's National Tourism Administration, 25 items were developed to measure the perceived quality of the specific historical and cultural destination, i.e. an ancient town in China.

There were five main sections to explore the five dimensions (Reliability, Responsiveness, Insurance, Empathy and Tangibility) of the perceived quality of the attraction with each dimension including 5 items (e.g. The authenticity and integrity of historical sites are well conserved; Prompt service to tourists; Making tourists feel safe during travelling; Providing special facilities and services for specific groups; Desirable sanitary conditions). Respondents were required to determine the degree to which each statement reflects their perception of the attraction and the services provided. All items used a five-point Likerttype scale ranging from $1=$ never to 5 = always.

Operationalisation of motivation. From the perspective of an anthropologist, tourists travelled to escape the routine of daily life and seek authentic experiences [11]. From a sociopsychological point of view, tourist motivation involved seeking and avoidance dimensions [40]. To measure tourist motivation, several studies used push forces such as the desire for escape, health and fitness, rest and relaxation, family togetherness and adventure as well as pull forces such as cultural attractions, beaches, recreation facilities, entertainment, natural scenery, parks and shopping [41, 42]. Based on these studies and considering the reality of the research object and part of the results of interviews with some tourists visiting a historical and cultural attraction, eight items including both push and pull forces were developed to measure tourist motivation. All items used a fivepoint Likert-type scale ranging from $1=$ not important at all to 5 = very important.

\section{Sample design and data collection}

A semi-constructed survey questionnaire was used to collect data regarding an ancient town of Sheqi, located in Henan province, middle part of China, which is a historical and cultural site. The data were gathered in May, 2019. A convenience sampling method was adopted because of limited time and manpower. The questionnaire was distributed at the exit and the service centre of the attraction. Visitors who finished their visitation of the ancient town were asked about their willingness to participate in the questionnaire survey. If they were willing to, they were asked to complete the questionnaire either on paper or on the mobile phone by scanning the QR code. A total of 1,500 questionnaires were distributed and 1,389 were completed. Thus, the response rate was 92.6 per cent.

\section{Reliability Test}

\section{Results}

Before evaluating the model, reliability and validity of the research instrument were tested. To delineate the underlying factors, an exploratory factor analysis (EFA) using the principle component method with orthogonal rotation was conducted simultaneously. As shown in Table 1, four factors were extracted from the variable of tourist experience, i.e. education, aesthetics, entertainment and escapism, based on the underlying items. Two factors were extracted from the variable of tourist motivation, i.e. push and pull motivations. Also, five factors, i.e. reliability, responsiveness, assurance, empathy and tangibility, were extracted from the variable of tourist satisfaction. The results of the reliability test showed that Cronbach's alpha coefficients of all variables were above the minimum of 70 [43], indicating that all the constructs were reliable.

\section{Measurement Model}

The reliability of the measurement model was tested using the confirmatory factor analysis. Several common model fit indices were used as criteria to judge the measurement tenability, NCI ( $\chi 2$ /df), CFI, TLI, RMSEA and SRMR. Table 2 shows the recommended values and test results for these indices.

Furthermore, psychometric properties of the measurement model were evaluated in terms of composite reliability and convergent validity. First, composite reliability was calculated as indicated by Fornell and Larcker [44], with the results ranging from .813 to .974 and exceeding the critical value of 0.7 [43]. Second, convergent validity was assessed by the average variance extracted. As indicated in Table 1 , the results were all above the recommended level of 0.5 , thus demonstrating that convergent validity was satisfied for the measurement model.

\section{Correlation Analysis among Variables}

Means, standard deviation and a correlation coefficient for tourist motivation, tourist experience, perceived quality and tourist satisfaction are presented in Table 3.

The results of the correlation coefficient between variables in Table 3 show that tourist motivation had a significant positive relationship with perceived quality $(\mathrm{r}=.751, \mathrm{p}<0.1)$, experience $(\mathrm{r}=.749, \mathrm{p}<0.1)$ and satisfaction $(\mathrm{r}=.723, \mathrm{p}<0.1)$. Perceived quality had a significant positive relationship with tourist ex- 
Table 1. Psychometric properties of the measurement model

\begin{tabular}{|r|c|c|c|c|c|}
\hline \multicolumn{1}{|c|}{ Constructs and Factors } & $\begin{array}{c}\text { Standardised } \\
\text { Loadings }\end{array}$ & $\begin{array}{c}\text { Variance } \\
\text { Extracted }\end{array}$ & Cronbach's a & Composite Reliability & Average Variance Extracted \\
\hline Experience & & $90.63 \%$ & & & 0.875 \\
\hline Education (ED) & 0.718 & & 0.971 & 0.965 & 0.878 \\
\hline Eesthetics (ES) & 0.731 & & 0.968 & 0.966 & 0.845 \\
\hline Escapism (EC) & 0.719 & & 0.961 & 0.956 & 0.798 \\
\hline Motivation & & & 0.945 & 0.940 & 0.523 \\
\hline Push (PS) & 0.807 & & & & 0.756 \\
\hline Perceived Quality & 0.8770 & & 0.828 & 0.813 & 0.827 \\
\hline Reliability & 0.679 & & 0.921 & 0.925 & 0.870 \\
\hline Responsiveness & 0.591 & & 0.955 & 0.950 & 0.882 \\
\hline Assurance & 0.562 & & 0.969 & 0.964 & 0.883 \\
\hline Empathy & 0.651 & & 0.960 & 0.958 & 0.869 \\
\hline Tangible & 0.671 & & 0.977 & 0.974 & 0.796 \\
\hline
\end{tabular}

Table 2. Goodness-of-fit indices for the measurement and structural models

\begin{tabular}{|c|c|c|c|}
\hline Index & $\begin{array}{c}\text { Recommended } \\
\text { Value }\end{array}$ & $\begin{array}{c}\text { Measurement } \\
\text { Model }\end{array}$ & $\begin{array}{c}\text { Structural } \\
\text { Model }\end{array}$ \\
\hline $\mathrm{NCl}\left(\mathrm{X}^{2} / \mathrm{df}\right)$ & $2.00-5.00$ & 3.098 & 2.51 \\
\hline $\mathrm{CFI}$ & $\geq .90$ & .914 & .926 \\
\hline $\mathrm{TLI}$ & $\geq .90$ & .907 & .941 \\
\hline $\mathrm{RMSEA}$ & $\leq .08$ & .077 & .073 \\
\hline SRMR & $\leq .10$ & .0043 & .029 \\
\hline
\end{tabular}

perience $(\mathrm{r}=.899, \mathrm{p}<0.1)$ and satisfaction $(\mathrm{r}=.837, \mathrm{p}<0.1)$. Tourist experience had a significant positive relationship with satisfaction $(\mathrm{r}=.873, \mathrm{p}<0.1)$. The findings provided initial support for the research hypotheses of Hl-H6. However, to verify the hypotheses, it is necessary to employ SEM to further explore relationships between variables.

\section{Structural Equation Modelling}

On the basis of the confidence in the measurement model established by the reliability and validity analysis, the structural equation modelling (SEM) analysis was conducted using the maximum likelihood estimation method to examine the relationships between each pair of constructs. The fit indices of the structural model indicated a good fit to the data with $\mathrm{NCI}=2.51$, CFI $=.926$, TLI $=.941$, RMSEA $=.073$, and SRMR $=.029$, as shown in Table 2.
Table 3. Means, standard deviation and correlation coefficient for variables

\begin{tabular}{|c|c|c|c|c|}
\hline & MO & PQ & EX & TS \\
\hline MO & 1.000 & & & \\
\hline PQ & $0.751^{* *}$ & 1.000 & & \\
\hline EX & $0.749^{* *}$ & $0.899^{* *}$ & 1.000 & \\
\hline TS & $0.723^{* *}$ & $0.837^{* *}$ & $0.873^{* *}$ & 1.000 \\
\hline Mean & 3.772 & 3.994 & 3.970 & 3.995 \\
\hline STD & 0.883 & 0.896 & 0.877 & 0.895 \\
\hline
\end{tabular}

Note: MO - means motivation; PQ - means perceived quality; EX - means experience; TS - means tourist satisfaction. ${ }^{* * *}$ - indicates $\mathrm{p}<.00$; ${ }^{* *}$ - indicates $\mathrm{p}<.01$; ${ }^{*}$ - indicates $\mathrm{p}<.05$.

The estimated standardised path coefficients between variables and the direction and significance of the hypothesised relationship between the four constructs are presented in Figure 2 and Table 4.

As shown in Figure 2 and Table 4, the six path coefficients were significant at $\mathrm{p}<.001$. As expected, tourist motivation had a significant positive impact on perceived quality $(\beta=.150, \mathrm{p}<$ $.001)$, tourist experience $(\beta=.783, \mathrm{p}<.001)$, and tourist satisfaction $(\beta=.121, \mathrm{p}<.001)$, and the effects were extremely significant $(\mathrm{p}<.001)$. According to the estimated standardised path coefficients, motivation had a greater impact on experience than on perceived quality and satisfaction. Thus, $\mathrm{Hl}, \mathrm{H} 2$ and $\mathrm{H} 3$ were supported. $\mathrm{H} 4$ and $\mathrm{H} 5$ suggested significant positive relationships between experience and perceived quality $(\beta=.804, \mathrm{p}<$ $.001)$, and experience and satisfaction $(\beta=.675, \mathrm{p}<.001)$, which were also strongly supported. Significant positive relationships 
Table 4. Direct, indirect and total effects between the four constructs

\begin{tabular}{|l|c|c|c|c|}
\hline \multicolumn{1}{|c|}{ Path } & Estimate & S.E. & Est./S.E. & $\begin{array}{c}\text { Two-Tailed } \\
\text { P-Value }\end{array}$ \\
\hline Motivation $\rightarrow$ Experience & .783 & .011 & 68.910 & .000 \\
\hline Motivation $\rightarrow$ Perceived Quality & .150 & .019 & 7.996 & .000 \\
\hline Motivation $\rightarrow$ Satisfaction & .121 & .023 & 5.313 & .000 \\
\hline Experience $\rightarrow$ Perceived Quality & .804 & .016 & 49.303 & .000 \\
\hline Experience $\rightarrow$ Satisfaction & .675 & .035 & 19.029 & .000 \\
\hline Perceived Quality $\rightarrow$ Satisfaction & .132 & .036 & 3.667 & .000 \\
\hline
\end{tabular}

between perceived quality and tourist satisfaction $(\beta=.132, \mathrm{p}<$ .001) put forward in H6 were also supported.

\section{Conclusions}

The findings of this study provided support for the positive significant effects of tourist experience $(\beta=.804, \mathrm{p}<.001)$ and tourist motivation $(\beta=.150, \mathrm{p}<.001)$ on perceived quality regarding a historical and cultural destination. Meanwhile, tourist experience was greatly affected by their motivation $(\beta=.783, \mathrm{p}<$ .001). Furthermore, it was found that these three variables influenced tourist satisfaction significantly. The findings indicated that, for a historical and cultural destination, tourist experience plays a very important role in tourists' behaviour concerning its significant linkages with tourist motivation, perceived quality and tourist satisfaction. These findings could provide managers of historical and cultural destinations with guidance for better understanding of visitors' experience, their motivation and how visitors' perception of the quality of the service provided is influenced, which will in turn affect tourist satisfaction and their behavioural intentions regarding future visits [10, 11, 31].

\section{Theoretical Implication}

In previous studies, there were abundant findings about each construct of tourist experience [32, 34], motivation [9, 10, $11]$ and perceived quality $[1,3,5]$. However, little attention has been paid to the relationships between these variables, especially to the relationship between tourist experience and tourists' perception of service quality. In some cases, they were even used interchangeably [6]. In this study, it was verified that tourist experience and perceived quality were different constructs, and tourist experience and motivation had a positive impact on perceived quality, which would further influence tourist satisfaction in the historical and cultural context. In addition, tourist experience was greatly affected by tourist motivation. The outstanding finding of this study is the important role of tourist experience in tourists' behaviour. It was believed that this study had the capability and potential of developing more precise studies and applications of tourist behaviour regarding historical and cultural destinations.

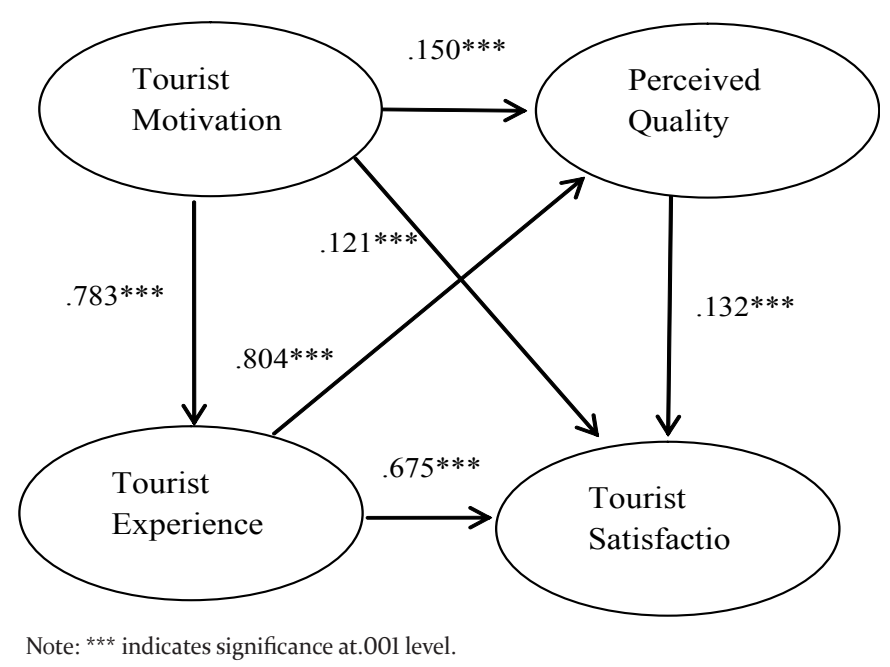

Figure 2. Hypothesised Model Test

\section{Managerial Implication}

The findings obtained from testing the proposed hypothetical model had managerial implications for the marketing success of the ancient town of Sheqi and other historical and cultural destinations. Since tourist experience plays so important a role, tourists' experiences in the attraction must be enhanced. First of all, in historical and cultural destinations, heritages should be carefully protected and preserved as well as fully exhibited and demonstrated to fulfil visitors' education, learning and appreciating demands [10]. Furthermore, dynamic activities getting tourists involved should be developed. It was found that many visitors came for education experience. Therefore, some workshops providing teaching, skill training and researching services should be available. In particular, for tourists under 18 and tourists with high education level and high monthly income, the special experience of co-creation may be of great attractiveness and a way to improve their satisfaction and loyalty.

It was demonstrated by the results of the empirical analysis that tourist motivation had a significant positive impact on perceived quality. Therefore, managers and marketers of historical and cultural destinations were expected to take multiple reasons and motivations into consideration when making marketing plans and strategies [10]. Investment should be made not only in protection and decoration of the attraction but also in organising enjoyable activities and events and launching publicity and propaganda through diverse platforms.

\section{Limitations and Future Research}

There were some issues associated with the limitations of this study. In terms of research samples, owing to the limitations of the research objects, only tourists visiting the small ancient town were surveyed, and most of the respondents came from the same province, which may not reflect general conditions of historical and cultural attractions in China. Limitations also existed in the historical and cultural destination typology, the selection of the variables and the corresponding hypothetical framework. Future studies may be conducted towards different historical and cultural attractions in different areas of China, and different antecedents and consequences related to perceived quality of historical and cultural destinations. 


\section{References}

1. Aaker D.A. (2009). Managing brand equity: Capitalizing on the value of a brand name. New York: Free Press.

2. Baker D.A., Crompton J.L. (2000). Quality, satisfaction and behavioral intentions. Annals of Tourism Research 27(3), 785-804. DOI: 10.1016/S0160-7383(99)00108-5.

3. Song H., Li G., Van Der Veen R., Chen J.L. (2011). Assessing Mainland Chinese Tourists' satisfaction with Hong Kong Using Tourist Satisfaction Index. International Journal of Tourism Research 13(1), 82-96. DOI: 10.1002/jtr.801.

4. Li G., Song H., Chen J.L., Wu D.C. (2012). Comparing mainland Chinese tourists' satisfaction with Hong Kong and the UK using tourist satisfaction index. Journal of China Tourism Research 8, 371-392. DOI: 10.1080/19388160.2012.729402.

5. Liu M.H., Yi S., Xia H.J. (2017). Study on the expansion of tourism satisfaction index system from international perspective. Tourism Research 9(2), 53-65. DOI: 10.3969/j. issn.1674-5841.2017.02.004.

6. Wang X., Mei H. (2006). Tourist satisfaction of tourism destination: model and empirical study. Journal of Beijing International Studies University (Tourism Edition) 137, 58-62. DOI: CNKI:SUN:JDEW.0.2006-07-000.

7. Pine B.J., Gilmore H.J. (1999). The experience economy: Work is theatre $\mathcal{E}$ every business a stage. Boston, MA: Harvard Business School Press.

8. Chen C.F., Chen F.S. (2010). Experience quality, perceived value, satisfaction and behavioral intentions for heritage tourists. Tourism Management 31, 29-35. DOI: 10.1016/j.tourman.2009.02.008.

9. Cini F., Kruger S., Ellis S. (2013). A model of intrinsic and extrinsic motivations on subjective well-being: The experience of overnight visitors to a national park. Applied Research in Quality of Life 8, 45-61.

10. Hsieh C.M., Chen T.P., Hsieh C.J., Tsai B.K. (2018). Moderating effect of membership status on the quality-valueloyalty chain at museums. Social Behavior and Personality, 46(1), 107-126. DOI: 10.2224/sbp.4073.

11. Yoon Y., Uysal M. (2005). An examination of the effects of motivation and satisfaction on destination loyalty: a structural model. Tourism Management 26(1), 45-56. DOI: 10.1016/j.tourman.2003.08.016.

12. Figler M.H., Weinstein A.R., Sollers J.J., Devan B.D. (1992). Pleasure travel (tourist) motivation: A factor analytic approach. Bulletin of the Psychonomic Society 30, 113-116. DOI: 10.3758/BF0333041.

13. Gitelson R.J., Crompton J.L. (1984). Insights into the repeat vacation phenomenon. Annals of Tourism Research 11(2), 199-217. DOI: 10.1016/0160-7383(84)90070-7.

14. Ryan R.M., Deci E.L. (2000). Self-determination theory and the facilitation of intrinsic motivation, social development, and well-being. American Psychologist 55, 68-78. DOI: 10.1037//0003-066X.55.1.68.

15. Crompton J.L. (1979). Motivations for pleasure vacation. Annals of Tourism Research 6(4), 408-424. DOI: 10.1016/0160-7383(79)90004-5.

16. Quan S., Wang N. (2004). Towards a structural model of the tourist experience: an illustration from food experiences in tourism. Tourism Management 25, 297-305. DOI: 10.1016/S0261-5177(03)00130-4.

17. Andereck K., Bricker K.S., Kerstetter D., Nickerson N.P. (2006). Connecting experiences to quality: Understanding the meanings behind visitors' experiences. In G. Jennings,
N.P. Nickerson (eds), Quality Tourism Experiences (pp. 8198), Burlington, MA: Elsevier Butterworth-Heinemann.

18. Noy C. (2007). The Poetics of tourist experience: An autoethnography of a family trip to Eilat. Journal of Tourism and Cultural Change 5(3), 141-157. DOI: 10.2167/jtcc085.0.

19. Cohen E. (2004). Contemporary tourism: Diversity and change. Oxford: Elsevier.

20. Li Y. (2000). Geographical consciousness and tourism experience. Annals of Tourism Research 27(4), 863-883. DOI: 10.1016/S0160-7383(99)00112-7.

21. Jennings G. (2006). Perspectives on quality tourism experiences: An introduction. In G. Jennings, N.P. Nickerson (eds), Quality Tourism Experiences (pp. 1-22), Burlington, MA: Elsevier Butterworth-Heinemann.

22. Prentice R.C. (2004). Tourist motivation and typologies. In A. Lew, M. Hall, A.M. Williams (eds.), A Companion to Tourism (pp. 261-79), Oxford: Pergamon.

23. Chen C.F., Chen F.S. (2010). Experience quality, perceived value, satisfaction and behavioral intentions for heritage tourists. Tourism Management 31(1), 29-35. DOI: 10.1016/j.tourman.2009.02.008.

24. Oliver R.L., Linda G. (1981). Effect of satisfaction and its antecedents on consumer preference and intention. Advances in Consumer Research 8, 88-93.

25. Chen C.C., Huang W.J., Petrick J.F. (2016). Holiday recovery experiences, tourism satisfaction and life satisfaction: Is there a relationship? Tourism Management 53, 140-147. DOI: 10.1016/j.tourman.2015.09.016.

26. Su L., Swanson S.R., Chen X. (2016). The effects of perceived service quality on repurchase intentions and subjective well-being of Chinese tourists: The mediating role of relationship quality. Tourism Management 52, 82-95. DOI: 10.1016/j.tourman.2015.06.012.

27. Wang X. (2011). The effect of unrelated supporting service quality on consumer delight, satisfaction, and repurchase intentions. Journal of Service Research 14, 149-163.

28. Parasuraman A., Zeithaml V.A., Berry L.L. (1985). A conceptual model of service quality and its implications for future research. The Journal of Marketing 49, 41-50.

29. Wu H.C., Li T. (2015). An empirical study of the effects of service quality, visitor satisfaction, and emotions on behavioral intentions of visitors to the museums of Macau. Journal of Quality Assurance in Hospitality and Tourism 16, 80-102.

30. Frochot I., Hughes H. (2000). Histoqual: the development of a historic houses assessment scale. Tourism Management 21(2), 157-167. DOI: 10.1016/S0261-5177(99)00045-X.

31. Hsieh C.M., Park S.H., Hitchcock M. (2015). Examining the relationships among motivation, service quality and loyalty: The case of the National Museum of Natural Science. Asia Pacific Journal of Tourism Research 20, 1505-1526.

32. Otto J.E., Ritchie J.R.B. (1996). The service experience in tourism. Tourism Management 17(3), 165-174. DOI: 10.1016/0261-5177(96)00003-9.

33. Kao Y.F., Huang L.S., Wu C.H. (2008). Effects of theatrical elements on experiential quality and loyalty intentions for theme parks. Asia Pacific Journal of Tourism Research 13(2), 163-174. DOI: 10.1080/10941660802048480.

34. Oh H., Fiore A.M., Jeoung M. (2007). Experience Economy Concepts: Tourism Applications. Journal of Travel Research 46(6), 119-132. DOI: 10.1177/0047287507304039.

35. Churchill G. (1979). A paradigm for developing better measures of marketing constructs. Journal of Marketing Research 16(1), 64-73. DOI: 10.2307/3150876. 
36. Parasuraman A., Zeithaml V.A., Berry L.L. (1994). Alternative scales for measuring service quality: a comparative assessment based on psychometric and diagnostic criteria. Journal of Retailing 70(3), 201-230. DOI: 10.1016/00224359(94)90033-7.

37. Kang G.D., Jame J., Alexandris K. (2002). Measurement of internal service quality: application of the SERVQUAL battery to internal service quality. Managing Service Quality: An International Journal 12(5), 278-291. DOI: 10.1108/09604520210442065.

38. Lam S.S., Woo K.S. (1997). Measuring service quality: a test-retest reliability investigation of SERVQUAL. International Journal of Market Research 39(2), 381. DOI: $10.2307 / 1251835$.

39. Llosa S., Chandon J.L., Orsingher C. (1998). An empirical study of SERVQUAL's dimensionality. Service Industries Journal 18(2), 16-44. DOI: 10.1080/02642069800000017.
40. Iso-Ahola S.E. (1982). Toward a social psychological theory of tourism motivation: A rejoinder. Annals of Tourism Research 9(2), 256-262. DOI: 10.1016/0160-7383(82)90049-4.

41. Pyo S., Mihalik B.J., Uysal M. (1989). Attraction attributes and motivations: A canonical correlation analysis. Annals of Tourism Research 16(2), 277-282. DOI: 10.1016/01607383(89)90077-7.

42. Yuan S., McDonald C. (1990). Motivational determinants of international pleasure time. Journal of Travel Research 29(1), 42-44. DOI: 10.1177/004728759002900109.

43. Hair J.F., Anderson R.E., Tatham R.L., Clack W. (1998). Multivariate data analysis with readings (5th Ed.). Englewood Cliffs, USA: Prentice-Hall.

44. Fornell C., Larcker D.F. (1981). Evaluating structural equation models with unobservable variables and measurement error. Journal of Marketing Research 18(2), 39-50. DOI: $10.1177 / 002224378101800104$.

Submitted: November 14, 2019. Accepted: February 21, 2020. 